AGRICULTURE AND BIOLOGY JOURNAL OF NORTH AMERICA

ISSN Print: 2151-7517, ISSN Online: 2151-7525, doi:10.5251/abjna.2011.2.9.1261.1269

(C) 2011, ScienceHu $\beta$, http://www.scihub.org/ABJNA

\title{
Post-harvest attributes and consumer acceptability of green mealies (Zea mays) stored at ambient and refrigeration temperatures in Swaziland
}

\author{
Michael T. Masarirambi ${ }^{1}$, Sifiso H. Makhubu ${ }^{1}$ Thokozile E. Sibiya $^{2}$ and Anthony N. \\ Mutukumira $^{3}$ \\ ${ }^{1 *}$ Horticulture Department, Faculty of Agriculture, University of Swaziland, P.O. Luyengo \\ M205, Luyengo, Swaziland \\ ${ }^{2}$ Consumer Sciences Department, Faculty of Agriculture, University of Swaziland, P.O. \\ Luyengo M205, Luyengo, Swaziland \\ ${ }^{3}$ Institute of Food Nutrition and Human Health, Massey University, Albany Campus, North \\ Shore Mail Centre, Auckland, New Zealand
}

\begin{abstract}
Maize (Zea mays) is the staple food of the Swazi people and many traditional societies in Africa. When freshly harvested, the product is referred to as green mealies and is highly valued in Southern Africa. Green mealies are highly perishable compared to dry maize because of their high water content which affects their keeping quality. There is need therefore to find suitable post-harvest handling methods to retard deterioration processes of green mealies. Thus, the main objective of this study was to investigate the consumer acceptability of boiled green mealies which were initially stored at various temperatures $\left(1.5^{\circ} \mathrm{C}, 5^{\circ} \mathrm{C}\right.$ and ambient temperature). The study also investigated the effect of storing samples under these conditions on total soluble solids (TSS) and mass loss. The study was carried out at the Food Science and Technology Laboratory of the University of Swaziland, Luyengo Campus. Two experiments were conducted where, in each experiment, there were three treatments (storage at $1.5{ }^{\circ} \mathrm{C}, 5{ }^{\circ} \mathrm{C}$ or ambient temperature) replicated three times. The treatments were arranged in a randomized complete block design (RCBD). Data pertaining to TSS, mass loss and sensory evaluation at 2, 4, 6,8 and 10 days after storage were collected. Total soluble solids ranged between 2.55 and $6.3 \%$ and mean mass loss ranged from 2.68 to $11.53 \%$ by the end of the experiment. There were significant $(p<0.05)$ differences with respect to the acceptance of the samples from various storage temperatures by a consumer panel. Green mealie bread or bolied green mealies previously stored at $1.5^{\circ} \mathrm{C}$ were most accepted by consumers followed by samples stored at 5 ${ }^{\circ} \mathrm{C}$ and lastly those stored at ambient temperature. All the samples of green mealies lost quality to a certain extent during storage which showed that loss of quality can not be stopped but can be minimised.
\end{abstract}

Keywords: Zea mays. Perishability. Keeping quality. Storage temperature. Consumer acceptability

\section{INTRODUCTION}

Maize (Zea mays L.) is the staple food of the Swazi people and is the most common crop grown in Swaziland (Dlamini, 2004). It is widely used in its dry state when ground to maize meal. Storage of dry maize is not a problem and can be over a prolonged period (Proctor, 1994). Dlamini (2004) reported that about $65-67 \%$ of the Swazi diet is based on maize products. Maize is ranked first in terms of field crop production and the most important source of carbohydrates in the Southern African Development Community (SADC) for human and animal consumption (FAO/CIMMYT, 1997; Burger, 2006; Gouse et al., 2006). Green mealies are an important meal during summer in Swaziland and the whole of Southern Africa region. In the region, green mealies are usually consumed boiled or as grains from roasted cobs (Madovi, 1981; Okuruwa, 1992; Shava et al., 2009) and sometimes the grains are ground to make mealie-bread in Swaziland and South Africa (Ogle and Grivetti 1985b; 1985c). All year production 
in the region is possible through the use of irrigation (Swabure and Zwane 2010; Fanadzo et al., 2010). Out of season green mealie production, mostly during the cool season is done in the Lowveld were temperatures are warm enough to sustain required photosynthesis of this $\mathrm{C}_{4}$ grass (Pursglove, 1983). The mealies are actively marketed in directmarketing channels such as farmers' markets and roadside stands, fresh, boiled, roasted or as green mealie bread.

Harvesting and handling are important agricultural operations which should be done carefully, as they have influence on subsequent processing and preservation of a product. The level of damage suffered by a crop during harvesting and handling can affect its marketable life. Therefore, green mealies for example should be hand picked to minimise damage. Ears are snapped down and away from the main stalk and stalk ends are trimmed short to prevent excessive moisture loss through transpiration (Peirce, 1987). Green mealies like other fresh horticultural crops are highly perishable when compared to dry maize because of their high water content (Wills et al., 1981; Relf, 1996; Kader, 2002; Suslow and Cantwell, 2006). Therefore, there is need to find appropriate post-harvest handling methods to preserve green mealies, as well as to retard the deterioration processes. Large amounts of green mealies get spoiled due to poor handling at and after harvesting and during marketing hence the need for this study. The objectives of this experiment were to determine consumer acceptability of green mealies previously stored at different temperatures and to find optimal refrigeration conditions that would minimize mass and quality loss of green mealies.

\section{MATERIALS AND METHODS}

Experimental Site, Layout and Management: This study was carried out in the Chemistry and the Food Science Laboratories at the University of Swaziland (Luyengo Campus) where storage of green mealies was done in two different storage rooms. The white green mealies "SC 701" were obtained from the University of Swaziland Farm. The farm is located at Luyengo, Manzini region, in the Middlevveld agroecological zone. The site has an average altitude of $750 \mathrm{~m}$ above sea level. Its mean annual rainfall is $980 \mathrm{~mm}$ per year where most of the rain falls between October and March. The farm is dominated by the Malkerns soil series, comprised of deep red loam soil, which is slightly acidic (Murdoch, 1968). The average winter temperature is $15^{\circ} \mathrm{C}$ while that of summer is about $27^{\circ} \mathrm{C}$. The "SC 701" white maize variety is a long season with desirable properties for use as green mealies and for making green mealiebread.

The green mealies were harvested from the farm early in the morning and transported to the University. One hundred and eighty green maize cobs, were harvested at the milk stage and kept with their husks at different temperatures which comprised of 3 treatments. Three temperatures used to store the green mealies were $1.5{ }^{\circ} \mathrm{C}, 5{ }^{\circ} \mathrm{C}$ and ambient temperature (Table,1). The mean ambient temperature during the study was $23.7^{\circ} \mathrm{C}$ (Table, 2). There were two storage refrigerators and a cupboard at ambient temperature. Temperatures in the two refregeration storage conditions used were maintained by means of avoiding regular opening of the storage rooms unnecessarily. Before the maize cobs were stored, twenty maize cob samples had their mass and total soluble solids measured. These two measurements (mass loss and total soluble solids) were done every two days and sensory tests after every five days.

Table 1: Treatments or storage regimes of green mealies (Zea mays) used in the study

\begin{tabular}{|l|l|}
\hline $\begin{array}{l}\text { Treatment } \\
\text { number }\end{array}$ & Treatment description \\
\hline 1 & Green mealies stored at $1.5^{\circ} \mathrm{C}$ \\
\hline 2 & Green mealies stored at $5^{\circ} \mathrm{C}$ \\
\hline 3 & $\begin{array}{l}\text { Green mealies stored at ambient } \\
\text { temperature }\left(23.7^{\circ} \mathrm{C}\right)\end{array}$ \\
\hline
\end{tabular}

Table2: Ambient temperatures recorded during the storage of green mealies (Zea mays).

\begin{tabular}{|l|c|c|c|}
\hline Day & \multicolumn{3}{|c|}{ Temperature $\left({ }^{\circ} \mathbf{C}\right)$} \\
\hline & Minimum & Maximum & Average temperature \\
\hline 1 & 26 & 30 & $28^{\star}$ \\
\hline 2 & 21 & 31 & 26 \\
\hline 3 & 22.5 & 22.5 & 22.5 \\
\hline 4 & 23.5 & 23.5 & 23.5 \\
\hline 5 & 21.5 & 20.8 & 21.1 \\
\hline 6 & 19 & 24.5 & 21.8 \\
\hline 7 & 22.7 & 26.5 & 24.7 \\
\hline 8 & 22.3 & 26 & 24.1 \\
\hline 9 & 23 & 20.5 & 21.8 \\
\hline 10 & 23 & 24 & 23.5 \\
\hline \multirow{2}{*}{$23.7{ }^{\circ} \mathrm{C}-$ Mean room temperature during the study } \\
period.
\end{tabular}

Experimental Design: Three storage treatments were employed in the experiment as described in 
Table 1. Three batches of 20 maize cobs each were assigned to each treatment, i.e. ambient/ room temperature $\left(23.7^{\circ} \mathrm{C}\right), \quad\left(5^{\circ} \mathrm{C}\right)$ and $\left(1.5^{\circ} \mathrm{C}\right)$. Each batch of 20 ears/cobs of maize acted as a block. The treatments were laid in a randomized complete block design (RCBD) replicated three times.

Data collection: Data were collected for total soluble solids (TSS), mass loss of green mealies and sensory tests using hedonic scales were conducted to determine consumer acceptability of maize products from the three storage regimes previously described.

Total Soluble Solids (TSS): Total soluble solids content was measured using an A-S-T Japan hand refractometer model $(0-32 \%)$ which is shown in Fig. 1 . The procedure for testing the total soluble solids of the green mealies firstly involved calibrating the refractometer using distilled water. Maize kennels were detached from the cob, crushed and the liquid was squeezed out of the kernels using a cheese cloth into a beaker. The beaker was held unshaken to allow the solids in the liquid to settle. When the solids had settled the liquid was then transferred for filtration where a filter paper and a funnel were used. The filter paper was suspended on a plastic funnel, to allow the clear liquid to flow to another beaker underneath. The purpose of filtration was to eliminate insoluble solids from the kennels liquid, thus extracting a clear liquid which was readable for TSS under the refractometer. After filtration, 2-3 drops of the clear liquid were placed on the refractometers' prism to read the amount of TSS through the eyepiece while facing light. Kernels randomly obtained from five maize cobs per treatment were used for measurement of TSS every two days starting from the time of storage up to day ten of storage.

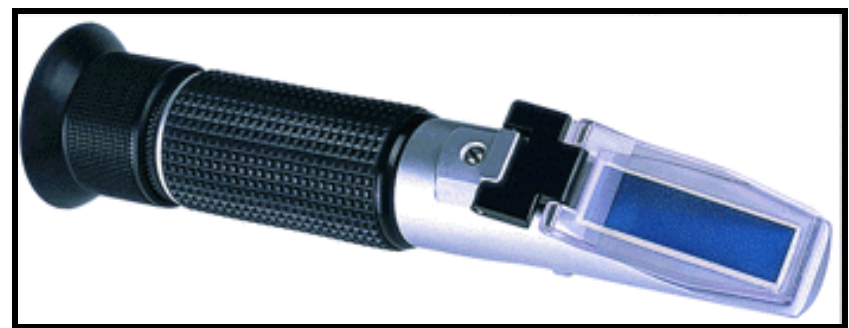

Fig. 1: The A-S-T Japan hand refractometer model 0 $32 \%$ used to evaluate TSS of green mealies (Zea mays).

Loss of mass: The mass of ears (cobs) was measured using a top-pan balance before storage and every two days there after. The procedure involved weighing 5 ears from each block and taking the average to represent a block and also weighing those marked cobs in each block. The measurements obtained were then expressed as a percentage (\%) of the initial mass taken soon after harvest. Sampling was done every two days where five maize cobs were used from each treatment.

Sensory Evaluation: Green mealies from each treatment whose husks had been removed were boiled for 1 hour. Sensory evaluation was used to determine consumer acceptability (O'Mahony, 1986; Meilgaard et al., 1991) of boiled green mealies. Green mealie bread was prepared using kernels (Fakudze, 2002) of ten cobs from each treatment. The same method of sensory evaluation like that of boiled mealies was used to determine consumer acceptability of the green mealies processed into bread. The sensory evaluation involved the use of 10 final year Bachelor of Food Science students at the University of Swaziland, randomly selected as panellists. Panellists evaluated on specific characteristics (colour, taste and mouth feel texture) using a 6-point hedonic scale. The scale was as follows; 1=dislike very much, 2=dislike moderately, $3=$ dislike slightly, 4=like slightly, 5=like moderately and $6=$ like very much.

Temperature: Minimum and maximum room temperatures were recorded daily from the first day of storage up to the last day i.e day 10. Minimum and maximum thermometers were installed inside the room where the green mealies were stored at ambient temperature. Minimum and maximum temperatures were recorded in the other storage rooms. The temperatures taken were recorded and mean temperatures were calculated and are shown in Table 2.

Data Analysis: The data which was collected on total soluble solids (TSS) as well as loss of mass were subjected to Analysis of Variance (ANOVA) using MASTAT-C package (Nissen, 1989). With sensory evaluation data, the scores were analysed using Statistical Package for Social Science (SPSS). Mean separation, where significant results were obtained was by Least Significant Difference (LSD).

\section{RESULTS}

Mass Loss: Losses in mass were significantly $(\mathrm{P}<$ 0.05 ) different between the storage temperature (5 ${ }^{\circ} \mathrm{C}, 1.5^{\circ} \mathrm{C}$ and $23.7{ }^{\circ} \mathrm{C}$ ) during storage period from 
day 2 up to day 10 of storage (Fig. 2). Loss in mass from day 2 of storage ranged from $2.68 \%$ to $3.08 \%$ at $5{ }^{\circ} \mathrm{C}$. At $1.5{ }^{\circ} \mathrm{C}$ the loss of mass in green mealies ranged from $2.63 \%$ to $2.55 \%$, while at ambient temperature $\left(26{ }^{\circ} \mathrm{C}\right)$, loss of mass ranged from 3.14 $\%$ and $3.89 \%$ with a least significant difference (LSD) of 0.528 at 0.05 alpha level. The mass of the stored $\left(5{ }^{\circ} \mathrm{C}\right)$ green mealies decreased at day 4 of storage where it declined by $4.5 \%$. Mealies stored at $1.5^{\circ} \mathrm{C}$ had an average mass loss of $2.36 \%$ while at ambient temperature $\left(25^{\circ} \mathrm{C}\right)$ an average loss in mass of $5.9 \%$ was obtained with a least significant difference (LSD) of 0.657 .

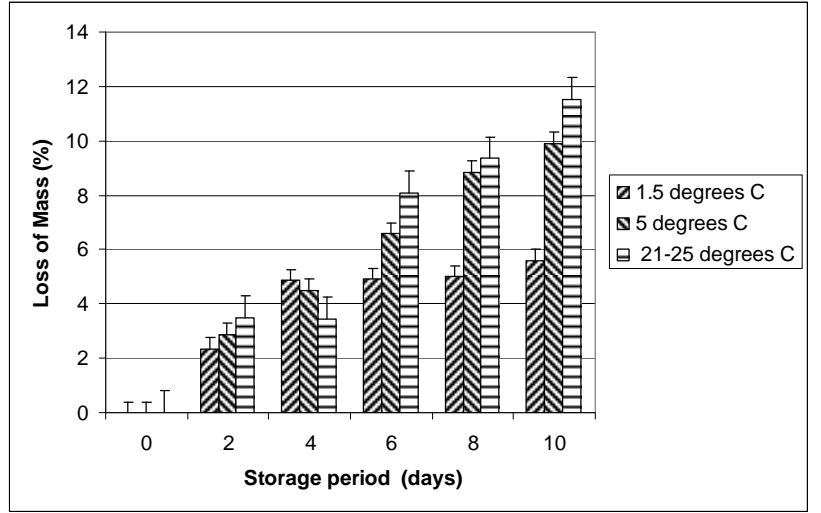

Fig. 2: \% Mass loss of green mealies (Zea mays) stored at different temperatures over 10 days. Vertical bars represent standard deviation above and below the mean.

On day 6 of storage at $5{ }^{\circ} \mathrm{C}$, a range of $5.89 \%$ to 7.3 $\%$ mass loss was recorded with an average of 6.57 $\%$. The green mealies sampled from $1.5{ }^{\circ} \mathrm{C}$ storage temperature recorded the least mass loss at day 6 with $4.4 \%$ while the green mealies held at ambient temperature $\left(23.8{ }^{\circ} \mathrm{C}\right)$ recorded an average mass loss of $8.08 \%$ with a least significant difference (LSD) of 1.56. A $5 \%$ decrease in mass was recorded on day 8 from green mealies sampled from $1.5{ }^{\circ} \mathrm{C}$ storage. The least significant difference (LSD) of 1.79 was attained on day 8 of storage. An average mass loss of $6.57 \%$ was recorded from green mealies held at $5{ }^{\circ} \mathrm{C}$. Mealies sampled at ambient temperature $(24$ ${ }^{\circ} \mathrm{C}$ ), had an average mass loss of $9.4 \%$. On day 10 of storage the highest loss in mass was attained from green mealies held at ambient temperature of 23.6 ${ }^{\circ} \mathrm{C}$, an average of $11.53 \%$ mass loss was recorded with a least significant difference (LSD) of 0.907 . This was followed by $9.91 \%$ loss recorded from maize sampled from $5{ }^{\circ} \mathrm{C}$ storage, and the least mass loss of day 10, $8.6 \%$, was recorded from maize stored at $1.5^{\circ} \mathrm{C}$, as shown in Fig. 2.

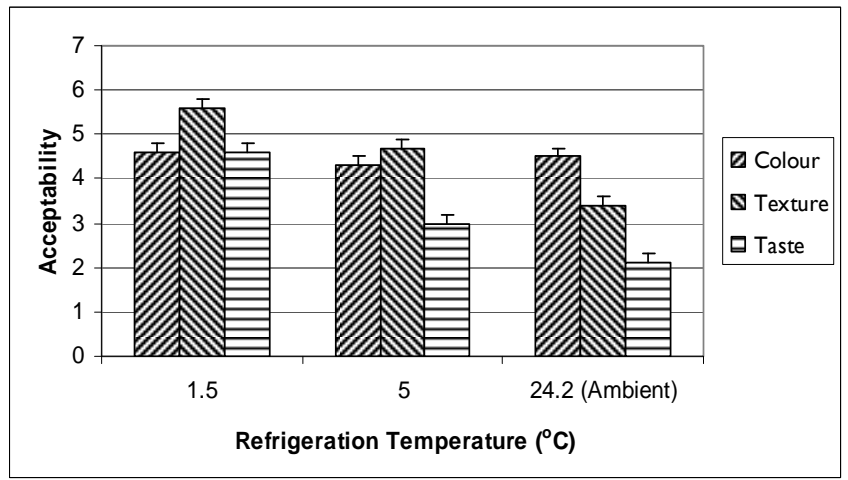

Fig. 3: Sensory scores for consumer acceptability of boiled green mealies (Zea mays) at day 5 of storage at different temperatures. Vertical bars represent standard deviation above and below the mean.

Sensory Evaluation: The differences in sensory scores of boiled green mealies previously stored at 5 ${ }^{\circ} \mathrm{C}, \quad 1.5{ }^{\circ} \mathrm{C}$ and ambient temperature, were significantly $(P<0.05)$ different for day 5 and 10 of storage. Figure 3 shows the results of sensory evaluation at day 5 of storage of the green mealies which were evaluated after boiling. Mealies previously stored at $1.5{ }^{\circ} \mathrm{C}$ scored the highest mean of 5.6 pertaining to texture, followed by those previously stored at $5{ }^{\circ} \mathrm{C}$ with 4.7 , and the least was 3.4 for boiled green mealies previously stored at ambient temperature of $24.2^{\circ} \mathrm{C}$.

The sensory mean scores for colour ranged between 4.3 and 4.6 where the highest mean (4.6) was obtained for green mealies previously stored at $1.5^{\circ} \mathrm{C}$, followed by ambient temperature with 4.5 and the least mean value of 4.4 for those previously stored at $5{ }^{\circ} \mathrm{C}$.. The means for taste, ranged between 2.1 and 4.6 for green mealies stored at $1.5^{\circ} \mathrm{C}$. This was followed by a sensory mean score of 3 from green mealies sampled from $5{ }^{\circ} \mathrm{C}$ storage and the mean 2.1 from mealies stored at ambient temperature of $24.2{ }^{\circ} \mathrm{C}$. The sensory score means for taste were relatively lower than the other two (colour and texture), at all the three different temperatures.

When the green mealie bread was sensory evaluated, texture recorded the highest sensory score followed in decreasing order by color and taste in all the three treatments as shown in Fig. 4. 


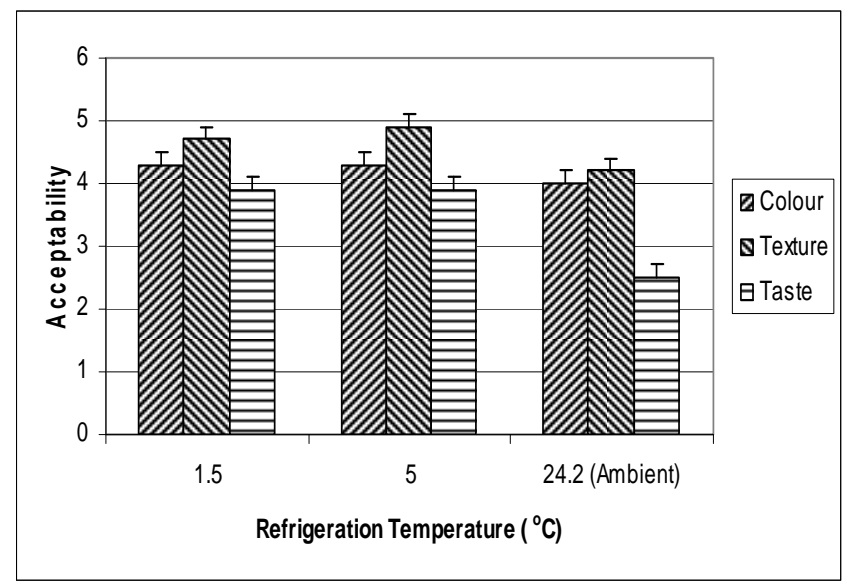

Fig. 4: Sensory scores for consumer acceptability of steamed green mealies (Zea mays) bread made on day $\mathbf{5}$ from green mealies stored at different temperatures.

Vertical bars represent standard deviation above and below the mean.

For green mealies previously stored at $5{ }^{\circ} \mathrm{C}$, the highest mean score of acccetability was 4.9 , followed by 4.7 for $1.5{ }^{\circ} \mathrm{C}$ storage, 4.2 was obtained from boiled mealies previously stored at ambient temperature of $24.2{ }^{\circ} \mathrm{C}$ (Fig. 4). Sensory score was 4.3 for both green mealies stored at $1.5^{\circ} \mathrm{C}$ and $5{ }^{\circ} \mathrm{C}$. The mean 4.0 was the least score recorded for green mealies stored at ambient temperature $\left(24.2^{\circ} \mathrm{C}\right)$. The sensory mean scores for taste were the lowest as compared to colour and texture scores with 2.5 mean score for samples from ambient temperature. The score of 3.9 was obtained from maize sampled from $1.5^{\circ} \mathrm{C}$ and from $5{ }^{\circ} \mathrm{C}$ storage.

Results obtained on day 10 of storage (for boiled green mealies) are shown in Fig. 5. Sensory scores for colour for green mealies stored at $1.5,5{ }^{\circ} \mathrm{C}$ and ambient temperature $\left(23.7{ }^{\circ} \mathrm{C}\right)$ were $4.95,4.85$ and 2.25 in decreasing order respectively. A decrease in taste scores was observed for mealies stored at 1.5 ${ }^{\circ} \mathrm{C}, 5{ }^{\circ} \mathrm{C}$ and ambient storage temperature, which were 3.6, 3.0 and 1.85 respectively. Texture acceptability scores where at $1.5^{\circ} \mathrm{C}$ storage was 4.5 ; at $5{ }^{\circ} \mathrm{C}$ was 4.7 and the least mean being 2.9 from storage at ambient temperature.

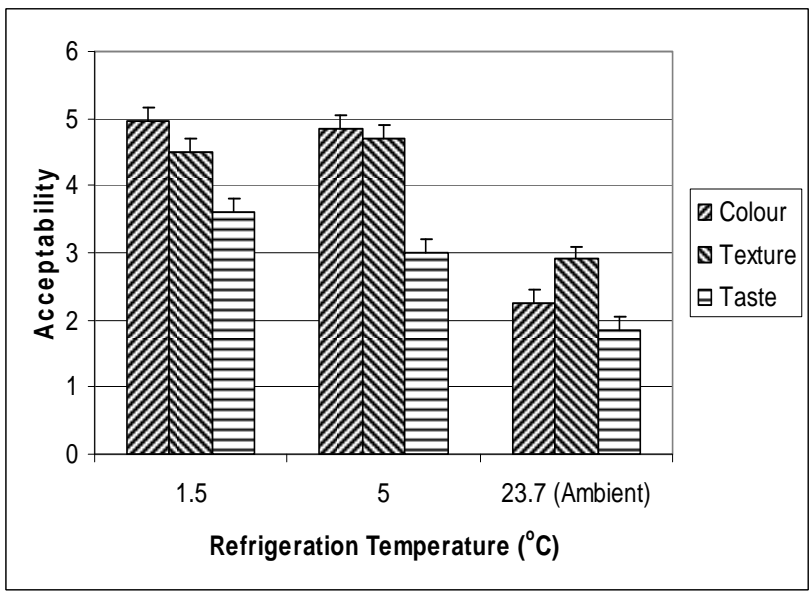

Fig. 5: Sensory scores of the consumer acceptability of boiled green mealies (Zea mays) on day 10 of storage at different temperatures.

Vertical bars represent standard deviation above and below the mean.

When green mealie bread was evaluated, as indicated by the overall acceptability on day 10 , where scores for colour were 5.2, 4.9, and 2.6 for maize stored at $1.5{ }^{\circ} \mathrm{C}, \quad 5{ }^{\circ} \mathrm{C}$ and ambient temperature $\left(23.7{ }^{\circ} \mathrm{C}\right)$ respectively. The highest sensory score of 5.3 was recorded for texture for the samples previously stored at $1.5{ }^{\circ} \mathrm{C}$. A score of 3.6 was obtained from samples stored at $5{ }^{\circ} \mathrm{C}$ while the sensory score of 3.1 was recorded from samples stored at ambient temperature $\left(23.7^{\circ} \mathrm{C}\right)$, as shown in Fig.6.

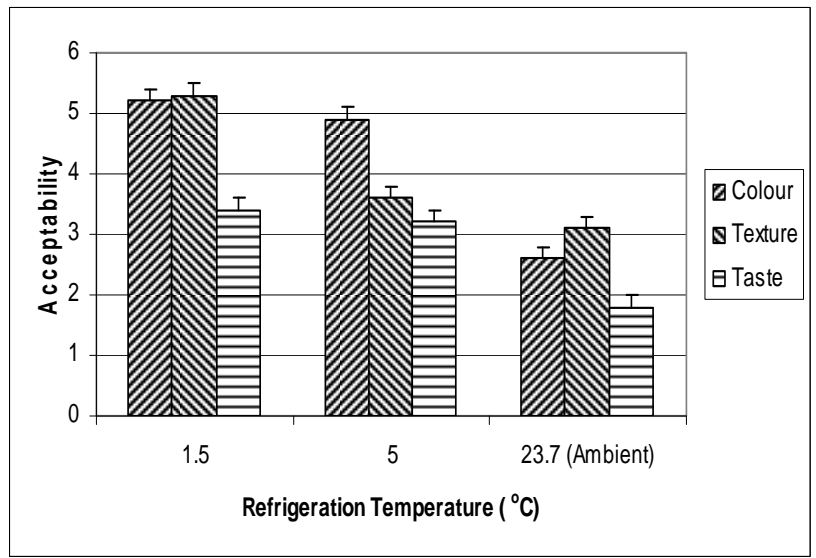

Fig. 6: Sensory scores and consumer acceptability of steamed green mealies (Zea mays) bread at day 10 of storage at different temperatures. Vertical bars represent standard deviation above and below the mean. 
Total Soluble Solids (TSS): Total soluble solids amongst the treatments from day 2 up to day 10 of storage showed significant $(P<0.05)$ differences. On day 2 of storage, an average of $6.3 \%$ TSS was recorded for green mealies stored at $1.5^{\circ} \mathrm{C}$, followed by an average TSS of $6.15 \%$ for samples stored at $1.5{ }^{\circ} \mathrm{C}$ and $4.9 \%$ for samples stores at ambient temperature $\left(26^{\circ} \mathrm{C}\right)$ with a least significant difference of 0.50 . The initial TSS readings were $8.7 \%, 7.7 \%$ and $74 \%$ taken from maize stored at $1.5{ }^{\circ} \mathrm{C}, 5{ }^{\circ} \mathrm{C}$ and ambient temperature respectively (Fig. 7).

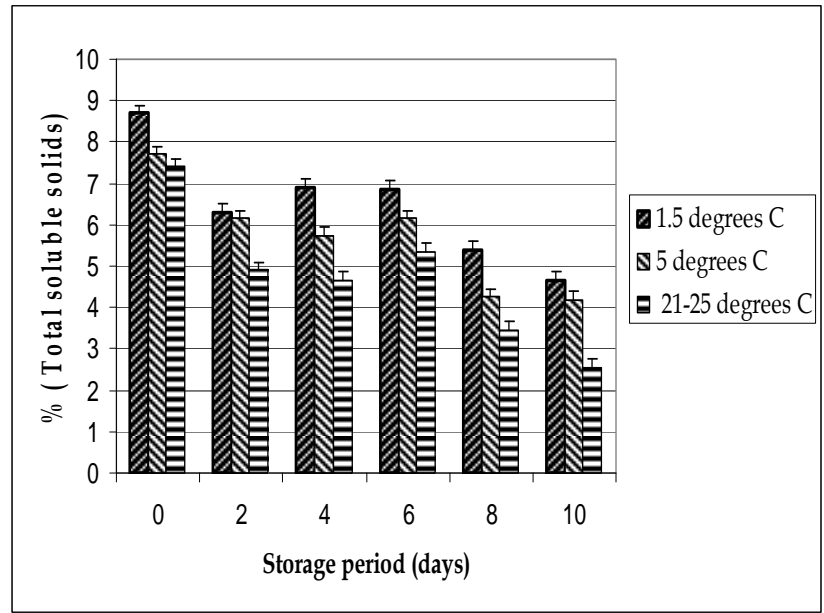

Fig. 7: Total soluble solids of green mealies (Zea mays) stored at different temperatures over 10 days. Vertical bars represent standard deviation above and below the mean.

On day 4 of storage the LSD was 1.56 , TSS of $6.9 \%$, $5.75 \%$ and $4.65 \%$ were recorded for green mealies stored at $1.5^{\circ} \mathrm{C}, 5^{\circ} \mathrm{C}$ and ambient temperature $\left(25^{\circ} \mathrm{C}\right)$ respectively. The TSS of mealies recorded at day 6 of storage where $6.85 \%, 6.62 \%$ and $5.35 \%$ for mealies stored at $1.5{ }^{\circ} \mathrm{C}, 5{ }^{\circ} \mathrm{C}$ and ambient temperature $\left(23.8{ }^{\circ} \mathrm{C}\right)$ respectively. However a decrease in TSS was observed from day 6 up to day 10 of storage. On day 6 , an average TSS of $6.85 \%$ was recorded from maize stored at $1.5^{\circ} \mathrm{C}$ followed by $6.15 \%$ at $5{ }^{\circ} \mathrm{C}$ and the least of $3.45 \%$ recorded for samples stored at ambient temperature $\left(23.8{ }^{\circ} \mathrm{C}\right)$ respectively. Total soluble solids on days 8 and 10 of storage were $5.4 \%$ and $4.65 \%$ for maize samples stored at $1.5{ }^{\circ} \mathrm{C}, 4.25 \%$ and $4.2 \%$ for samples stored at $5{ }^{\circ} \mathrm{C}$ and the lowest values recorded for samples previously stored ambient temperatures which were $3.45 \%$ and $2.55 \%$ respectively (Fig.7).

\section{DISCUSSION}

The losses in mass were significantly different between the storage temperature regimes during the study period. The rate of metabolism in a fresh commodity is temperature dependent (Kader, 2002). There was however no significant difference observed among blocks suggesting that storage conditions where relatively uniform per given treatment or storage regime. Cummulative losses in mass increased with time because higher losses were observed on day 10 when compared to those recorded on day 2. During the study period, green mealies stored at $1.5^{\circ} \mathrm{C}$ had lower losses which were almost constant from day 4 up to day 8 of storage, followed by those stored at $5^{\circ} \mathrm{C}$ and lastly at ambient temperature storage. Water loss is the main cause of deterioration because it results not only in direct quantitative losses (loss of salable weight), but also in appearance (wilting and shrivelling), textural quality (softening, flaccidity, limpness, loss of crispness and juiciness), and nutritional quality (Kader, 2002). Samples stored at $5^{\circ} \mathrm{C}$ showed no significant loss in mass on days 2 and 3 . The rate of mass loss by green mealies stored at ambient temperature declined steadily day by day from day six up to the last day i.e. day 10. With storage time the amount of water held by a fresh commodity decreases with time so does subsequent water loss and hence mass loss. In previous work Verstreken et al. (1995) reported that there was an interaction that existed between storage conditions and loss in mass. This phenomenon could be similar to the results of this experiment where mass loss increase was observed with increase in storage temperature. Rodov et al. (2000) reported similar results of sweet corn storage, however their conditions of storage were more superior than ours in that they additionally employed nested modified-atmosphere packages to maintain quality. The method was successfully tested during a trial shipment of sweet corn from Israel to Europe (Rodov et al., 2000). As temperatures were relatively high and uncontrolled at ambient temperature the highest loss in mass of green mealies was recorded. The green mealies at ambient temperature were subjected to desiccation as the temperatures were much higher and drier air was present in the storage room when compared to those stored in controlled temperature conditions. Temperature is the environmental factor that most influences the deterioration rate of harvested commodities (Kader, 2002) and hence the need for its control. 
Oxygen from the air broke down carbohydrates in the kernels of the green mealies into carbon dioxide, water and energy. When water and heat were lost, a loss in mass occured. At higher temperatures higher respiration rates were possible thus a higher loss in mass also. In the case of controlled temperatures like $5{ }^{\circ} \mathrm{C}$ and $1.5{ }^{\circ} \mathrm{C}$, the heat produced by respiration was quickly eliminated and it was released in small amounts as compared to the ambient temperature stored green mealies. Fresh produce cannot replace carbohydrates or water after harvest (Wilson, 1999). Respiration uses stored starch or sugar and will stop when reserves of these are exhausted. The decline in mass loss with time under storage was caused by the fact that the carbohydrates which were being converted to energy, were getting exhausted during the process and that remaining water got more tightly bound to commodity particles. This was explained by Kader (2002) who reported that all fresh crops respire and are of high water content and thus are subjected to mass loss, desiccation and mechanical injury. Maintaining high relative humidity is sometimes difficult because refrigeration removes moisture to some extend (Wilson, 1999). Thus a considerable amount of water loss was expected which contributed to mass loss. The crops were also susceptible to attack by bacteria and fungi resulting in pathological breakdown. In maize stored at ambient temperature, (day 6) of storage, fungal attack was visible on the husks, and the samples were drier than the ones stored at $1.5{ }^{\circ} \mathrm{C}$ or $5^{\circ} \mathrm{C}$.

Results showed that the consumer acceptability of green mealies may be affected by storage temperature and period of storage. Higher means of accetability were obtained in boiled mealies previously stored at $1.5^{\circ} \mathrm{C}$ followed by treatments in decrasing order of $5{ }^{\circ} \mathrm{C}$ and ambient temperature. These results showed that mealies stored at $1.5^{\circ} \mathrm{C}$ were more acceptable compared to those previously stored at $5^{\circ} \mathrm{C}$ and ambient temperature, in decreasing order. Taste was the attribute which was differently scored depending on prior storage condition and duration as perceived by the consumers. Generally the lower the temperature of storage and the shorter the duration the more the mealies or their products were acceptable most probably so because that is when high sugar contents prevailed. The rate of sugar to starch conversion which is undesirable in sweet corn is lower at relatively lower temperatures (Kader, 2002). This phenomenon suggests that the stored green mealies lost sugar over the storage period at different temperature conditions (King, 2007). Sugar was lost over the storage period by green mealies as the sensory evaluation panellists reported less sweetness of boiled green mealies previously stored at ambient temperature, followed by those stored at 5 ${ }^{\circ} \mathrm{C}$ and the ones which were from $1.5{ }^{\circ} \mathrm{C}$ were relatively sweeter as from the ratings. The same observations were made on the green mealie bread made from mealies previously stored at the various temperatures. In this case, also the sugar content in the bread was low in such a way that comments on the need to have more sugar added were raised by the panellists. Similarly Burgmans and Lill (1987) used panelits to test consumer perceptions on sweet corn in New Zealand while investigating preferences of various cultivars.

Our results suggest that the colour of the green mealie bread was not affected as well as the texture. This means that when the green mealies were processed into another product (bread) other than just boiling them, they became more acceptable to consumers used in our test panel. The results showed that texture was the least affected characteristic as far as previous temperature of storage was concerned.

There were significant differences in total soluble solids between the storage temperatures during the storage period. The significant differences were observed from day 2 up to day 10 . Total soluble solids decreased rapidly in samples stored at ambient temperature followed by those stored at $5{ }^{\circ} \mathrm{C}$ then the least losses were observed in mealies stored at $1.5^{\circ} \mathrm{C}$. The losses in TSS may be attributed to the loss of sugars which were converted to starch during storage (King, 2007). The TSS of green mealies are largely made up of sugars with some organic compounds and other phyto-chemicals. This agrees with Peirce (1987) who reported that higher temperatures accelerated sugar loss in sweet corn which is similar to green mealies. Suslow and Cantwell (2006) recommended temperatures close to $0{ }^{\circ} \mathrm{C}$ for sweet corn storage in order to maintain quality. It remains to be seen of the quality of the product of roasted green mealies previously stored near $0{ }^{\circ} \mathrm{C}$. The results of this experiment may also be related to the suppression of metabolism in samples at low temperatures affecting the conversion of sugar to starch and suppression of respiration rate.

\section{CONCLUSION AND RECOMMENDATIONS}

All samples of green mealies lost quality to a certain level while in storage at various temperatures, which suggested that the loss of quality cannot be stopped 
but can be minimised. Storage of green mealies at different temperatures resulted in significantly different losses in mass and TSS. Green mealies stored at $1.5{ }^{\circ} \mathrm{C}$ experienced relatively low quality losses when compared to those stored at $5{ }^{\circ} \mathrm{C}$ and ambient temperature in decreasing order. Sensory attributes scores and TSS decreased with time during the study suggesting that loss of quality of green mealies was difficult to control under the experimental conditions used. Low temperature storage $\left(1.5^{\circ} \mathrm{C}\right.$ and $\left.5^{\circ} \mathrm{C}\right)$ when compared to ambient temperature was more effective in maintaining some of the quality attributes of green mealies. The green mealies stored at $1.5^{\circ} \mathrm{C}$ were the most acceptable to consumers on the basis of sensory evaluation, followed by those previously stored at $5{ }^{\circ} \mathrm{C}$ and the least acceptable were those stored at ambient temperature $\left(24^{\circ} \mathrm{C}\right)$. It is recommended that green mealies should be stored at $1.5^{\circ} \mathrm{C}$ soon after harvest to keep them fresh for a number of days. Mass loss was more rapid during the earlier stages of storage; therefore treatments aimed at reducing moisture loss should be applied as early as possible after harvest. It is also, recommended that a study similar to this one be done involving the storage of green mealies at temperatures below $0{ }^{\circ} \mathrm{C}$.

\section{REFERENCES}

Burger, D. (2006). Agriculture and land affairs.

http://www.info.gov.za!aboutsalagric1and.htm\#field crops. 05/02/20008

Burgmans, J.L. and Lill, R.E. (1987). Sweet corn: Observations on supersweet cultivars for processing and fresh market use in New Zealand. New Zealand J. Expt. Agric, 15:199-203

Dlamini, H. N. (2004). Improving the Nutritive Value of Green-mealie Bread and Soft Porridge Using the Soya Bean Meal as the Therapeutic Diets for People Living with HIVIAIDS. Unpublished B. Sc. dissertation, University of Swaziland, Luyengo, Swaziland.

Fakudze, S. (2002). Developing New Products from Green Mealies, Unpublished B.Sc. Dissertation, University of Swaziland, Luyengo, Swaziland

Fanadzo, M., Chiduza, C. and Mnkeni, P.N.S. (2010). Overview of smallholder irrigation schemes in South Africa: Relationship between farmer crop management practices and performance. African J. Agric.Res., 5 (25):3514-3523

Food and Agricultural Organization of the United Nations (FAO) and International Maize and Wheat Improvement Centre (CIMMYT), (1997). White Maize a Traditional Food Grain in Developing Countries. Rome, Italy.
Gouse, M, Pray, C., Schimmelpfennig, D. and Kirsten, J. (2006). Three seasons of subsistence insect-resistant maize in South Africa: Have smallholders benefited? AgBioForum, 9(1): 15-22

Kader, A. A. (2002). Postharvest Technology of Horticultural Crops. University of California, Division of Agriculture and Natural Resources. 2nd Edition, Publication 3311, Berkeley, CA, USA.

King, M (2007). Florida Food Fare.

http://sarasota.extension.ufl.edu/FCSIFlaFoodFare/SweetC orn.htm.23/03/2008

Madovi, P.B (1981). Food handling in Shona villages of Zimbabwe. Ecology Food Nutri., 11 (3):133-144

Meilgaard, D., Civille, G.V., Carr, B.T. (1991). Sensory Evaluation Techniques. CRC Press. Boca Raton, FL , New York, NY. USA.

Murdoch, G. (1968). Soils and Land Capability in Swaziland. Ministry of Agriculture and Co-operatives, Mbabane, Swaziland.

Nissen, O. (1989). MStat-C. A micro-computer program for the design management and analysis of agronomic research experiments. Michigan State University. East Lansing. Michigan. USA.

Ogle, B.M. and Grivetti, L.E. (1985b). Legacy of the chameleon: edible wild plants in the Kingdom of Swaziland, Southern Africa. A cultural, ecological, nutritional study. Part II. Ecol Food and Nutr. 17:1-30.

Ogle, B.M.and Grivetti, L.E. (1985c). Legacy of the chameleon: edible wild plants in the Kingdom of Swaziland, Southern Africa. A cultural, ecological, nutritional study. Part III. Ecol Food and Nutr. 17:3140.

Okoruwa, A. E (1992). Utilization and Processing of Maize. IITA Research Guide No. 35. International Institute of Tropical Agriculture (IITA), Ibadan, Nigeria.

O'Mahony, M. (1986). Sensory Evaluation of Food. Marcel Dekker, Inc. New York, NY, USA.

Peirce, L.C. (1987). Vegetables: Characteristics, Production, and Marketing. John Wiley \& Sons Inc., New York, NY, USA.

Proctor, D. L. (1994). Grain Storage Techniques. Evolution and Trends in Developing Countries. FAO Agricultural Services Bulletin 109, FAO, Rome, Italy.

Purseglove, J. W.(1983). Tropical Crops. Monocotyledons, $3^{\text {rd }}$ Edition.Longman, London, England.

Relf, M., (1996). Florida Food Fare

http://sarasota.extension.ulf.edu/FCS/FlaFoodFare/Sw eetcorn.htm.22/08/2007 
Rodov, V., Copel, A., Aharoni, N., Aharoni, Y., Wiseblum, A., Horev, B. and Vinokuv, Y. (2000). Nested modified-atmosphere packages maintain quality of trimmed sweet corn during cold storage and the shelf life. Postharvest Bio. Technol.,18 (3):259-266

Shava, S., O'Donoghue, R., Krasny, M.E., and Zazu, C. (2009). Traditional food crops as a source of community resilience in Zimbabwe. International $\mathrm{J}$. African Renaissance, 4 (1):1-21

Suslow, T. V. and Cantwell, M. (2006). Sweet Corn. Recommendations for MaintainingPostharvest Quality.

http://rics.ucdavis.edu/postharvest2/Produce/ProduceF actsneg/com.shtml. 28/02/2008.

Swabure, O. and Zawe, C. (2010). The elusive multiple uses of irrigation water: some of the forgotten issues in smallholder irrigation schemes designing in Zimbabwe. J. Sustainable Dev. Africa, 12 (3):70-86

Verstreken, E., Garcia, J. L., Ruiz-Altisent, M. and De Baerdemaeker, J (1995). Control Applications in Post-
Harvest and Processing Technology. Elsevier Science Ltd, The Boulevard, Langford Lane, Kidlington, Oxford, OX5 1 GB, UK.

Wills R., Lee T., Graham D., McGlasson B. and Hall, E. (1981). Post-harvest: Introduction to the Physiology and Handling of Fruit and Vegetables, Kensington. NSW, New South Wales University Press. United Kingdom.

http://www.fao.org/docrep/T0073E/T0073E09.HTM\#Ap pendix $\% 2011 \% 20$ -

$\% 20$ Information $\% 20$ and $\% 20$ training $\% 20$ sources. $20 / 03 / 2008$

Wilson L. G. (1999). Postharvest Handling and Cooling of Fresh Fruits, Vegetables, and Flowers for Small Farms. North Carolina Cooperative Extension Service. North Carolina

http://www.ces.ncsu.edu/depts/hort/hil/hil-800.html. 20/03/2008 